\title{
Longitudinal Leadership Capacity Growth among Participants of a Leadership Immersion Program: How Much Does Structural Diversity Matter?
}

\author{
Jasmine D. Collins \\ Assistant Professor \\ Agricultural Education \\ University of Illinois at Urbana-Champaign \\ David M. Rosch \\ Associate Professor \\ Agricultural Education \\ University of Illinois at Urbana-Champaign
}

\begin{abstract}
Numerous studies have provided evidence that interracial interaction can contribute to the development of leadership skills and behaviors for university students. Yet, little empirical research has been dedicated to understanding the effects of structural (compositional) racial diversity within leadership programs on program participant outcomes. This study examined the impact of the structural racial diversity of 50 leadership program sessions on student leadership capacity gains over time. A total of 667 participants in sessions coded as either "High," "Moderate," or "Low" with regard to racial diversity within the session served as the sample. Results from data collected immediately prior to, directly after, and 3-4 months after program participation suggest the training effects of a leadership initiative may be augmented by the recruitment of racially diverse participants.
\end{abstract}

\section{Introduction}

Within the past 45 years, the United States population has witnessed a marked increase in the racial/ethnic diversity of its residents. In 1970, White residents made up $87.5 \%$ of the total U.S. population (U.S. Census Bureau, 2012). Today, the United States is reportedly $72.4 \%$ White, 12.6\% Black/African American, 5\% Asian/Native Hawaiian/Other Pacific Islander, 2.9\% Two or More Races and 6.2\% Other (U.S. Census Bureau, 2012). Concomitantly, residents who identify as Hispanic/Latino have increased from 4.5\% in 1970 to $16.3 \%$ in 2010 (U.S. Census Bureau, 2012). It is projected that by the year 2044, the United States will reach the "majorityminority" tipping point, with residents who report their race/ethnicity as something other than non-Hispanic White alone making up $50.1 \%$ of the population (Colby \& Ortman, 2015).

These broader demographic shifts have influenced racial and ethnic demographic changes on today's college campuses (Gutiérrez, 2011; Hurtado, 2007). In the fall of 1976, White students made up $84 \%$ of total postsecondary enrollment (National Center for Education Statistics, 2016). Today, the percentage of college students who identify as White has dropped to 58\%, with Hispanic, Asian/Pacific Islander, Black, and American Indian/Alaska Native students 
representing $17 \%, 7 \%, 14 \%$, and $.08 \%$, respectively (NCES, 2016).

With this diversification of the student body comes the responsibility to assess the extent to which existing campus resources and activities serve as a benefit for historically marginalized populations. Moreover, an opportunity exists to investigate the impact of increasingly diverse learning environments on learning outcomes for both White and non-White college student populations. Thus, the present study examines the impact of structural racial diversity within sessions of a leadership program, specifically the LeaderShape Institute, on the longitudinal leadership development of university students who participate within them.

Benefits of Structural Racial Diversity and Interracial Interaction. Structural diversity refers to the numerical representation of various racial and ethnic groups on campus (Hurtado, Milem, Clayton-Pederson, \& Allen, 1998). Largely in response to the landmark University of Michigan cases (Gratz v. Bollinger, 2003; Grutter v. Bollinger, 2003), which cited a diverse student body as a compelling reason to uphold the use of race-conscious admissions policies, research intended to demonstrate beneficial outcomes of racially diverse post-secondary environments has flourished. Past research suggests that the structural diversity of an institution can increase the likelihood that students from differing backgrounds will interact with one another (Gurin, Dey, Hurtado, \& Gurin, 2002), and serves as a significant predictor of such interaction more powerfully than other institutional characteristics such as geographic setting and Carnegie Classification (Antonio, 2001a; Pike \& Kuh, 2006). Additional research has linked cross-racial interaction to greater openness to diversity (Chang et al., 2006); improved sense of belonging on campus (Laird, 2005); increased intellectual engagement and cognitive development (Bowman, 2013; Chang et al., 2006; Gurin et al., 2002); and heightened cultural and civic engagement (Antonio, 2001b; Gurin et al., 2002). In many cases, these findings emerge even when controlling for race or self-reported predisposition to engage with diverse peers. These findings have led many scholars to advocate for supporting student interaction in racially diverse environments (Antonio, 2001a; Chang, Denson, Saenz, \& Misa, 2006; Gurin et al., 2002; Pike \& Kuh, 2006).

In addition to these outcomes, numerous studies have provided evidence that interracial interaction can contribute to the development of leadership skills and behaviors for university students (Antonio, 2001b; Bowman, 2013; Kezar \& Moriarty, 2000). In fact, participating in conversations across racial lines is one of the most potent predictors of student socially responsible leadership development (Dugan, Kodama, \& Gebhardt, 2012; Dugan \& Komives, 2010) and has been shown to noticeably affect leadership development among White men and women as well as African American women (Kezar \& Moriarty, 2000).

The effects of positive interracial interaction on leadership development are critically important to consider within a higher education context, particularly when defining leadership as a collaborative process aimed at shared common goals (Dugan and Komives, 2007; Rost, 1993). The overwhelming majority of university campuses that utilize leadership curricula explicitly include the need to collaborate productively with others, act in ethical ways, and serve as a role model for others (Owen, 2012). These learning outcomes often implicitly require students to create relationships with others based on authentic interaction. With the wealth of empirical support of the benefits of cross-racial and the inherently interactive nature of leadership 
programs, the relative dearth of research designed to examine the effects of structural diversity within leadership programs is surprising. Our study is designed to fill, in part, this noteworthy gap.

In response to the notion that increased structural diversity in postsecondary settings leads to racial balkanization (the tendency of students to self-select racially homogenous friendship groups), Antonio (2001a) asserts that "socialization across race in a specific contextoutside the comfortable, perhaps routine interactions with best friends" is critical in "developing increased cultural awareness and commitment" to racial understanding "above and beyond other behaviors that previous research have shown are important" (p. 80). Thus, participation in a social-justice-oriented leadership program designed to provide an immersive off-campus experience, such as the LeaderShape Institute, provides a worthwhile avenue through which to explore the effects of racial diversity within a formal leadership program on longitudinal student leadership development.

\section{Our Conceptual Model of Leadership Capacity and Student Development}

Most contemporary conceptualizations of leadership describe effective leaders as those able to collaborate with followers to affect real change through a process of ethical, multidirectional influence focused on shared purposes (Rost, 1993; Yukl, 2010). To act in such ways, recent research has called for leadership education programs to focus on helping students develop broad-based capacity that encompasses leadership skill (the knowledge and abilities of leadership), motivation to lead (the desire and energy to act as a leader), and leader self-efficacy (the confidence that one's efforts will lead to success) (Keating, Rosch, \& Burgoon, 2014). Without these capacities, students may not possess the facility to enact leadership behaviors, which Keating, et al. (2014), define as the "Ready, Willing, and Able" leadership competency model.

Leadership skill. Within the "Ready, Willing, and Able" model, leadership skill encompasses: (a) "Transformational" skill, where the effectiveness of leaders stems from the capacity to build authentic and transformational relationships, inspire peers to higher standards and goals, adhere to broad ethical standards that serve, and create sustainable and positive community change (Burns, 1978); (b) "Transactional" skill, defined as the ability to create a motivating system of work within a team to achieve goals, where leadership and the work of a team serve as transactions between leaders and followers (Bass, 1998); and (c) "Ethical" skill, which is the capacity to lead in ways that adhere to societal and organizational standards (Brown, Treviño, \& Harrison, 2005). While aspects of transformational and ethical leadership standards are often touted as more valuable than transactional behaviors (Dinh, Lord, Gardner, Mueser, Liden, \& Hu, 2014), all are often necessary in leading complex contemporary organizations.

Motivation to lead. Chan and Drasgow (2001) delineate three constructs that encompass an individual's motivation to lead: (a) Students' inclination and desire to think of themselves as leaders of their peers ("Affective-Identity" motivation); (b) The strength of their sense of responsibility to lead their peers ("Social-Normative" motivation); and (c) The degree to which students avoid conducting a self-centered calculation of how leading will result in their own personal benefit ("Non-Calculative" motivation). Motivation to lead has been shown as a factor 
in leader success in professional organizations (Amit \& Bar-Lev, 2013; Derue \& Ashford, 2010) and more recently in collegiate settings (Rosch, Collier, \& Thompson, 2015). Given the degree to which the particular leadership immersion program focused on social justice as an outcome, we also considered students' motivation to advocate for social issues important to them ("Social Issues Advocacy") as a measure of motivation to lead in this context.

Leader self-efficacy. Lastly, leader self-efficacy refers to students' confidence that their engagement in leadership-oriented behaviors will lead to success (Hannah, Avolio, Luthans, \& Harms, 2008; Murphy, 1992). Presumably, potential leaders are more likely to engage in the behaviors of leading if they believe their actions would make a positive and successful difference. Leader self-efficacy has been correlated with the success rate of leaders in a variety of professional settings (Avolio, Reichard, Hannah, Walumbwa, \& Chan, 2009; Hannah, Avolio, Luthans, \& Harms, 2008; Machida \& Schaubroeck, 2011) and has been shown more recently in studies in postsecondary institutions (Dugan, Garland, Jacoby, \& Gasiorski, 2008).

A model of leadership that examines students' leadership confidence, motivation, and skill is important to our research given what is known about the differentiated ways students of color and White students conceptualize and practice leadership. Students of color and women report lower levels of confidence and tend to place less emphasis on formal positions of authority than their white male peers (Dugan, 2006; Kezar \& Moriarty, 2000; Rosch, Stephens, \& Collins, 2015) for whom holding an elected office position serves as the strongest extracurricular predictor of leadership skill (Kezar \& Moriarty, 2000). In regard to motivation to lead, African American, Asian American, and Latino/a students are often motivated to engage in leadership opportunities to contribute to social change or due to a strong feeling of personal responsibility to their peers to do so (Arminio et al., 2000; Dugan, Komives, \& Segar, 2008).

Research Questions. This study examined the degree to which session racial diversity within a leadership session predicts longitudinal leadership development in students. Within this effort, we included the following research questions:

1. To what extent does session racial diversity affect the degree of leadership gains students report within an immersion leadership program?

2. To what extent do differences emerge between students of color and White students in leadership gains with regard to varying degrees of session diversity?

\section{Methods}

Population and Sample. All data were collected at Institute sessions, hereafter called "sessions," sponsored by LeaderShape, Inc., a not-for-profit private organization that partners with over 100 university campuses, mostly within the United States but with a small number in Canada, Mexico, and the Middle East, to host locally-based sessions that adhere to one common curriculum. Each session lasted for six days, and was designed for the purpose of teaching broadbased leadership competencies that are applicable in a variety of circumstances relevant to educational and professional environments. Significant aspects of the program curriculum were based on teaching inclusive practices of leadership and concepts of social justice as part of the responsibility of leadership in modern society (www.leadershape.org). The program curriculum incorporates large group-lecture style, small group discussion, and hands-on activity 
components. Over 4,000 university students participate in approximately 85 sessions each year. We initially chose the LeaderShape Institute both for its national prominence and international recognition among leadership educators, and because the goals of the program - to provide students the leadership tools necessary to create positive change in their organizations and communities - is shared by many co-curricular leadership programs within the United States (Owen, 2012).

An open call during the fall 2013 semester to institutions that host sessions yielded 31 universities interested in participating in this research study during the 2013-2014 and 2014-2015 academic years. Within these 31 universities, 41 campus-based sessions occurred across the two years, out of the approximately 170 sessions that occurred across all institutions. These participating universities were diverse in terms of size, control (e.g. public or private), admissions selectivity, and faculty research output. In addition to these 41 campus-based sessions, data were gathered at nine national sessions open to participants from any university and hosted directly by LeaderShape, Inc. Table 1 lists the specific post-secondary institutions that volunteered to participate within this research effort.

Table 1. List of participating institutions

\begin{tabular}{ll}
\hline San Francisco Bay Area Consortium & Ohio State University \\
\hline Boise State University & Penn State University \\
\hline Boston College & South Florida Consortium Institutions \\
\hline Bowling Green State University & Tulane University \\
\hline Central Michigan University & University of Alabama \\
\hline Clemson University & University of Georgia \\
\hline College of Charleston & University of Illinois \\
\hline Colorado State University & University of Iowa \\
\hline Denison University & University of Kansas \\
\hline East Tennessee State University & University of Michigan \\
\hline Eastern Michigan University & University of North Carolina Chapel Hill \\
\hline Elmhurst College & University of North Carolina Wilmington \\
\hline Florida State University & University of Tennessee Chattanooga \\
\hline Indiana University & University of Wisconsin LaCrosse \\
\hline Lehigh University & Nine National Sessions \\
\hline
\end{tabular}

A total of 2,405 students were initially included within this study and completed hardcopy pre-tests of their leadership capacity prior to participating within their sessions. These pretests consisted of 86 likert-scale (agree-disagree) items and a number of demographic and leadership involvement questions. From these, a total of 667 students (28\% of the initial sample) additionally completed post-tests immediately after their sessions (often while still at the program site) and follow-up tests administered by inviting students to complete an electronic survey by email 3-4 months after the conclusion of their session. The likert-scale items in the immediate-post and 3-4 month follow-up surveys were identical to the scale items in the pre-test. 
The students who completed all three phases of this data collection process comprise the analytic sample for our study.

Of these students, 30\% ( $\mathrm{n}=202)$ were in their first year of study, 29\% $(\mathrm{n}=196)$ identified as sophomores; $28 \%(\mathrm{n}=184)$ as juniors; $7 \%(\mathrm{n}=47)$ as seniors; $3 \%(\mathrm{n}=23)$ as graduate students, and $2 \%(n=15)$ did not report a class year. With regard to gender, approximately $67 \%(\mathrm{n}=445)$ of participants in sample identified as a woman, while $30 \%(\mathrm{n}=201)$ identified as a man, $1 \%(\mathrm{n}=5)$ identified as transgender; and $2 \%(\mathrm{n}=16)$ did not report a gender identification. With respect to racial identification, 54\% $(\mathrm{n}=357)$ identified as White, $15 \%(\mathrm{n}=99)$ as African-American, $7 \%$ $(\mathrm{n}=47)$ as Asian-American, 9\% $(\mathrm{n}=62)$ as Latino/a, 8\% $(\mathrm{n}=52)$ as multi-racial, and; $1 \%$ as Middle Eastern $(n=3)$, while $6 \%$ of participants $(n=47)$ did not report. To produce an appropriate degree of statistical power to analyze the degree to which students' self-identified race was predictive of leadership development within the context of varying degrees of diversity within sessions, we recategorized race into a dichotomous White/Non-white variable.

Concerned about potential bias introduced through self-selection in survey participation, we conducted extensive analysis of the participation rates in the post-test and the follow-up test. For the post-test, we employed logistic regression to estimate participation as predicted by pretest responses, using multivariate and univariate regression. These tested participant self-reported social identities and pre-test responses to the relevant leadership scale measures we included within the study (see Table 1). No differences were identified between post-test participants and post-test non-participants on any of these measures. Of greater concern was the substantively lower response rate to the three-month follow-up survey invitation. We estimated the same logistic regressions to predict participation from the pre-test responses, and additionally included in the analysis the participants' changes between pre-test and post-test scores on the eight leadership scales - effectively estimating whether pre-test-to-post-test changes predicted followup test participation.

Of these 32 coefficients estimated, only one variable predicted follow-up survey participation. Participants who reported higher non-calculative motivation to lead scores on the pre-test were slightly more likely to participate in the follow-up test $(\mathrm{t}=4.10, \mathrm{p}<.001)$, suggesting that of all measured psychometric constructs, only participants who report leading without regard to their own personal gain would also be more likely to respond to an online survey invitation. With only this qualification, we proceeded with confidence that the participants in the follow-up test had no statistically significant differences from non-participants in the follow-up test.

Defining "Diverse” Leadership Sessions. Despite purported benefits, researchers are only beginning "to establish the theoretical and empirical links in determining the optimal conditions under which these benefits operate and how they may work differently for particular types of students" (Hurtado, 2003, p.188). Therefore, creating a definition for a "diverse" campus or leadership session, remains unsettled and problematic. We attempt to follow the spirit of O'Connor's premise in the Grutter v. Bollinger (2003) Supreme Court's decision - that adequate representation from all respective races building to a critical mass is important to avoid tokenization. 
We used a broad framework and definition of "diversity" that represented more than simply a dichotomous split of majority and minority students with regard to racial identity. We defined a "High Diversity" session as one where no single racial group represents a statistical majority (more than $50 \%$ of participants), while at least two other racial groups were represented by at least $10 \%$ of participants. We defined a "Moderate Diversity" session as comprised of at least two racial groups in which no less than $20 \%$ of program participants identified, even if one racial group could be categorized as a majority. We lastly defined a "Low Diversity" session as one where more than $50 \%$ of participants identified with one dominant racial group; while no other racial groups represented more than $15 \%$ of program participants. Within this categorization, we chose to identify "diversity" as not just the significant presence of one nonWhite racial group, but rather a critical mass of students from several varying racial groups. Even sessions consisting of predominantly African American students are not considered "high diversity" if other racial groups have low representation. Implementing this framework led to the creation of 24 "High" diversity sessions $(n=1105), 9$ "Moderate" sessions $(n=410)$, and 17 "Low" sessions $(\mathrm{n}=890)$.

Instrumentation. Our study was designed to measure the degree that session racial diversity affects broad-based leadership capacity growth. We therefore assessed such growth in students' leadership skills, confidence in leading, and motivation to engage in leadership behaviors. To assess students' capacity within these areas, we used five different scales that incorporated a total of eight subscales. See Table 2 for an overview.

Table 2. Overview of leadership scales variables

\begin{tabular}{lll} 
Capacity & Scale & $\begin{array}{l}\text { Cronbach } \\
\text { Alpha }\end{array}$ \\
\hline Leadership Skill & Leadership Behaviors Scale - Transformational skills & .87 \\
& Leadership Behaviors Scale - Transactional skills & .72 \\
& Ethical Leadership Scale (ELS) & .88 \\
\hline Motivation to Lead & Motivation To Lead Scale - Affective Identity & .84 \\
& Motivation To Lead Scale - Non-calculative & .85 \\
& Motivation To Lead Scale - Social-normative & .92 \\
& Social Issues Advocacy Scale (SIAS) & .92 \\
\hline Leader Self-Efficacy & Self-Efficacy for Leadership (SEL) scale & .86 \\
\hline
\end{tabular}

Leadership skill. We measured leadership skill through three sub-scales: The Leader Behavior Scale (Podsakoff, MacKenzie, Moorman, \& Fetter, 1990), a popular and noncopyrighted 28-item instrument includes two sub-scales respectively focused on transformational $\left(\mathrm{LBS}_{\mathrm{F}}\right)$ and transactional $\left(\mathrm{LBS}_{\mathrm{A}}\right)$ leadership. A sample item for transformational behavior is, "I help other group members develop a team attitude and spirit among ourselves." A sample item for transactional leadership is, "I always give positive feedback when other group members perform well." We chose the LBS due to its use, for many years, as a broad measure of transformational leadership unassociated with the narrower Full-range Transformational Leadership Model and its respective Multifactor Leadership Questionnaire (Bass \& Avolio, 
1997). The LBS has been in use for over 20 years as a psychometric tool (Yukl, 2010) in both business and education settings, with Cronbach reliabilities ranging from .71 to .89 (Yukl, 2010). Within our study, Cronbach alpha scores ranged from .72 to .87.

We also utilized the Ethical Leadership Scale, a 10-item measure designed to measure the degree to which participants incorporate ethical behavior into their leadership values and planned behaviors (Brown et al., 2005). The ELS is correlated with the Idealized Influence scale within the popular Multi-Factor Leadership Questionnaire (Bass \& Avolio, 1997), measuring aspects of transformational leadership. While ethical behavior and transformational leadership represent theoretically related but distinct concepts (Bass, 1998), confirmatory factor analysis shows that the ELS measures a leadership capacity distinct from transformational leadership (Brown, et al., 2005). Moreover, initial psychometric examination of the ELS showed no significant relationship with social desirability measures or social identity demographic factors (Brown, et al). Within our research, ELS Cronbach alpha scores were strong (.88).

Leadership confidence. To assess students' confidence in leading, we utilized the SelfEfficacy for Leadership (SEL) scale, an 8-item measure of a person's confidence in engaging in leadership behaviors (Murphy, 1992). The SEL has been in use for 20 years in professional and educational environments and, like the LBS, has undergone extensive psychometric examination (Hoyt, 2005). A sample item is, "I know how to encourage good group performance." Research has shown that internal reliability is good, i.e., above .76 (Murphy \& Ensher, 1999), and the scale has been shown to possess convergent and discriminant validity when used with measures of self-esteem and leadership experiences (Hoyt, 2005). Within our study, internal reliability scores were strong at .86 .

Leadership motivation. Motivation to engage in leadership behaviors was measured using the Motivation to Lead (MTL) scale (Chan \& Drasgow, 2001), a 27-item measure equally divided across measures of affective-identity (AI), non-calculative (NC), and social-normative (SN) motivations to lead (Chan \& Drasgow, 2001). The MTL assesses the degree to which people feel "called" to lead as well as the pressure they feel and energy they possess to engage in leadership behaviors. The AI scale concerns the degree to which an individual is personally drawn to leadership roles and includes items such as, "Most of the time, I prefer being a leader rather than a follower when working in a group." The NC scale concerns the degree to which a person avoids rationally calculating the individual costs and benefits of holding a leadership position and includes items such as, "I never expect to get more privileges if I agree to lead a group." The SN scale is used to determine the degree to which a person leads due to a sense of duty or responsibility to others and includes items such as, "People should volunteer to lead rather than wait for others to ask or vote for them." The scale has been used primarily in professional and public organizations and has alpha reliabilities ranging from a low of .65 for the NC scale to a high of .91 for the AI scale. The MTL has recently been extended to the field of higher education as a tool to measure student leadership development (Rosch, 2014). Within our study, Cronbach alpha scores ranged from a low of .84 for the Social-Normative subscale to a high of .92 for the Affective-Identity subscale.

Social issues advocacy. Due to the LeaderShape curriculum focus, in part, on the application of social justice behaviors, we also included an adapted version of the Social Issues 
Advocacy Scale (Nilsson, Marszalek, Linnemeyer, Bahner, \& Misialek, 2011), designed to assess a person's motivation to publicly advocate for social issues considered both socially just and important to the person completing the measure. Aspects of political advocacy (i.e. motivation to vote, lobby, or campaign for people or political issues) encompassed in the original scale were not included in the current study. Language within each item was also adapted for an educational environment, where phrases such as "I am professionally responsible to..." were changed to "I am personally responsible to..." Sample items within the SIAS include, "I am personally responsible to confront friends and colleagues who display signs of discrimination," and "I use social media to advocate for social issues that are important to me." While the scale has been in use for less time than the others, and therefore possesses fewer psychometric markers of strength, the original research conducted to create and validate the scale indicates an acceptable degree of convergent validity with measures of multicultural empathy, as well as discriminant validity when measured with items on self-esteem and life satisfaction. Within our study, Cronbach alpha scores were strong at .92 .

Data Analysis. To determine the degree to which session racial diversity - and students' self-identified race in combination with session racial diversity - are associated with capacity gains, we utilized the longitudinal nature (i.e. at least three measurement points within each participant) of our dataset to conduct mixed-design analyses of variance using each scale measurement of leadership capacity, respectively, as a dependent variable. This design, also called split-plot analysis of variance (or SPANOVA) is named as such due to the nested blocking structure of a dataset for which it is applied - where split plots of data are nested in whole plots, which are themselves nested within blocks. In the case of this research study, the blocks represent phases of data collection (e.g. a pre-test, post-test, and months-later follow-up); the whole plots represent the degree of racial diversity within a leadership session; and the split-plots are comprised of students from various races. Whereas a traditional ANOVA or t-test are limited to single cross-sections of data, such as comparing post-test scores in one group to post-test scores in another, a SPANOVA, can include all phases of data collection within a single analysis, and allow researchers to investigate the trajectory of development over time (Huck \& McLean, 1975). Such analysis is a more powerful way to measure outcomes where individual participants have been subjected to repeated measures.

We conducted a series of eight SPANOVA analyses, examining the effects of session diversity and students' self-identified race on each of the eight leadership capacity scales included within the study. Given the degree to which gender identity has been shown to effect leadership development (e.g. Kezar \& Moriarty, 2000), we also included gender as a co-variate to ensure that variation in scores associated with gender identity did not affect our analysis.

To directly investigate the degree to which session racial diversity contributed to the longitudinal trajectory of leadership capacity gains in students, we examined the F-statistic result for our diversity level statistic (i.e. high, medium, or low) within the multivariate SPANOVA analysis, which controlled for students' gender and race. However, to explore the degree to which students' self-identified racial identity served as a predictor of leadership capacity change across different levels of session racial diversity, the F-statistic for students' race in the multivariate SPANOVA analysis did not serve as an appropriate indicator (this number instead represents only the independent contribution of students' race to capacity gains, controlling for 
session racial diversity and students' gender). For this investigation, we examined the follow-up between-subjects effects from each SPANOVA analysis, attending to the F statistic generated by the interaction of students' race and the degree of racial diversity within the session. This statistic indicates the degree to which White and non-White students exhibit different trajectories of growth across varying levels of session racial diversity.

\section{Results}

The overall means and dispersion statistics relevant to our examination of student leadership capacity for the study sample are displayed in Table 2 . When analyzing overall scores without regard to race or session racial diversity, students generally reported higher scores during the post-test period of data collection immediately following their sessions compared to during their pre-test and data collected during the follow-up period occurring three to four months later. Generally, scores remained elevated several months later, compared to pre-test scores.

Table 3. Overall means and dispersion of leadership capacity variables

\begin{tabular}{llll} 
Scale & Pre-test $\mu(\sigma)$ & Post-test $\mu(\sigma)$ & Follow-up-test $\mu(\sigma)$ \\
\hline Transformational Skill & $7.56(.89)$ & $8.34(.89)$ & $7.91(1.00)$ \\
Transactional Skill & $8.08(1.20)$ & $8.55(1.26)$ & $8.21(1.33)$ \\
Ethical Leadership Skill & $7.97(.93)$ & $8.54(.94)$ & $8.34(1.06)$ \\
Motivation to Lead - Affective Identity & $6.41(1.56)$ & $6.53(1.64)$ & $6.35(1.57)$ \\
Motivation to Lead - Non-calculative & $7.54(1.27)$ & $8.31(1.35)$ & $7.54(1.50)$ \\
Motivation to Lead - Social Normative & $6.83(1.13)$ & $7.07(1.29)$ & $6.48(1.16)$ \\
Social Issues Advocacy & $7.16(1.28)$ & $8.07(1.22)$ & $7.57(1.36)$ \\
Leader Self-Efficacy & $7.35(1.21)$ & $8.28(1.08)$ & $7.84(1.36)$ \\
\hline
\end{tabular}

We then conducted a series of eight SPANOVA analyses, one for each leadership scale. The condensed results of our respective analyses can be found in Table 4, which shows the degree to which session racial diversity contributes to students' gains in leadership capacity (i.e. the first line in the table within each measure, labeled "Session Diversity"), as well as the degree to which differences emerge between students of color and White students in leadership gains across leadership programs of varying degrees of diversity (i.e. the second line in the table within each measure, labeled "race"). 
Table 4. Results of SPANOVA analyses

\begin{tabular}{lllll} 
Scale & Variable & $\mathrm{F}$ & $\mathrm{df}$ & $\mathrm{p}$ \\
\hline Transformational Skill & Session Diversity & 1.89 & 4,1196 & .11 \\
\multirow{3}{*}{ Transactional Skill } & Race & 0.22 & 4 & .93 \\
& Session Diversity & 2.20 & 4,1196 & .07 \\
Ethical Leadership Skill & Race & 0.60 & 4 & .67 \\
\multirow{2}{*}{ Motivation to Lead - Affective Identity } & Session Diversity & 1.54 & 4,1156 & .19 \\
& Race & .031 & 4 & .87 \\
& Session Diversity & 3.40 & 4,1172 & $.009^{* *}$ \\
Motivation to Lead - Non-calculative & Race & 1.59 & 4 & .17 \\
& Session Diversity & 2.30 & 4,1170 & $.05^{*}$ \\
Motivation to Lead - Social Normative & Race & 0.97 & 4 & .42 \\
\multirow{3}{*}{ Social Issues Advocacy } & Session Diversity & 2.48 & 4,1162 & $.04^{* *}$ \\
& Race & 3.45 & 4 & $.01^{* *}$ \\
Leader Self-Efficacy & Session Diversity & 1.11 & 4,1160 & .35 \\
& Race & 0.51 & 4 & .73 \\
& Session Diversity & 7.56 & 4,1170 & $<.0001^{* * *}$ \\
\hline
\end{tabular}

Note: $* p<.05 . * * p<.01 .{ }^{* * *} p<.001$.

Our results suggest that session diversity serves as a significant predictor of longitudinal leadership capacity growth for students regarding their motivation to lead stemming from all three areas (affective-identity, non-calculative, and social normative), as well as in students' leader self-efficacy development. For each significant finding, the taper in scores from post-test to follow-up measurement 3-4 months later was smaller for High diversity sessions than for Low diversity sessions.

Students' race significantly interacted with session racial diversity in one area - socialnormative motivation to lead. Figures 1 and 2 graphically display the trajectory of these scores for White and Non-white students, respectively. Within this area of leadership capacity development, White students seemed to display a steeper decline in their sense of responsibility for providing leadership themselves within less racially diverse sessions. Students of color seemed less affected by the racial diversity within the room, showing a relatively similar trajectory of development in both low-diversity and high-diversity sessions. 


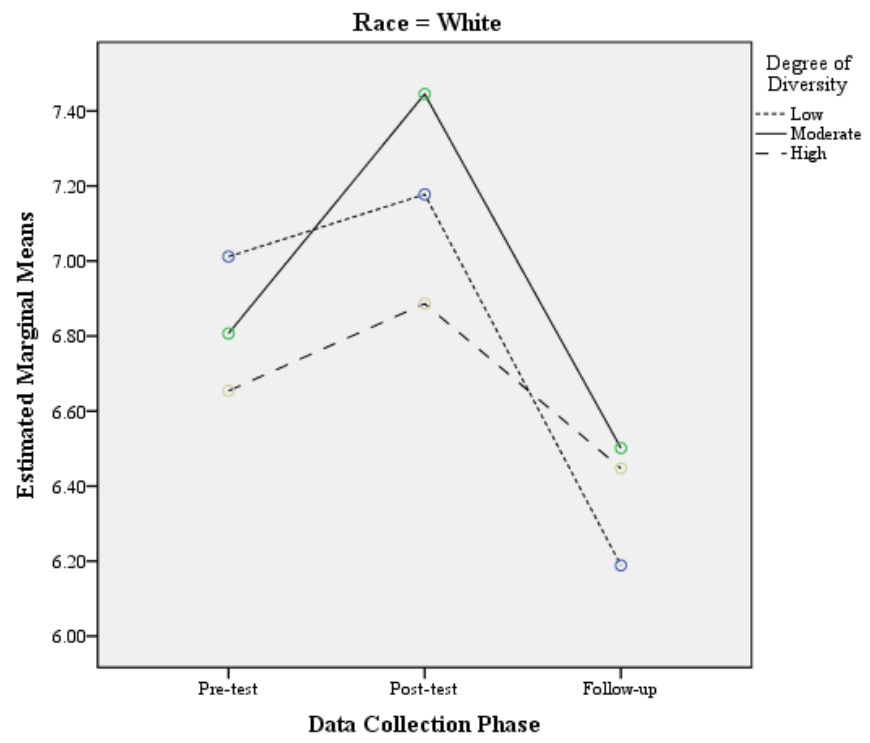

Figure 1. Social-normative Motivation to Lead Scores for WHITE students

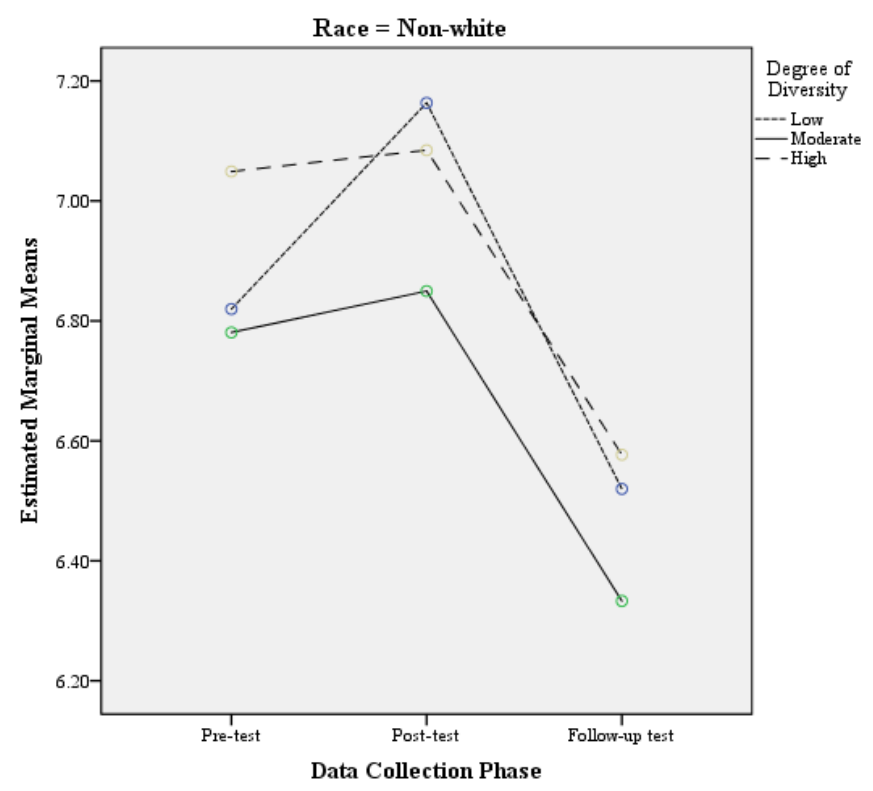

Figure 2. Social-normative Motivation to Lead Score for NON-WHITE students

\section{Discussion}

Our research focused on the degree to which session racial diversity within an immersion leadership program predicts longitudinal leadership development in students, particularly with respect to comparing these effects between students of color and their White peers. Our findings suggest that while the "skill" areas of leadership development (e.g. transformational, transactional, and ethical leadership skill) may not be deeply affected by who is present in the room during the leadership session, the aspects of leadership development that are more internal (i.e. motivation and confidence) may be so influenced. Indeed, students' long-term leader self- 
efficacy development seemed particularly sensitive to the degree of racial diversity within their sessions. Our results also suggest that development related to students' motivation to lead seem affected by the degree to which sessions are racially diverse. Within sessions with a high degree of racial diversity, students seemed to retain a greater degree of motivation to lead stemming from both their internal identity as a leader as well as a sense of responsibility to their groups compared to sessions that possessed a smaller degree of racial diversity within its participants.

Somewhat curiously, however, given these findings, the longitudinal changes in students' leadership capacities did not differ much based on race. Only the trajectories of students' development of a capacity for social-normative motivation to lead seemed to vary by race when analyzed across leadership sessions with varying degree of session racial diversity. In this area, the substantive difference was that White students expressed more volatility in their scores over time compared to students of color.

Implications. These findings suggest several noteworthy implications for leadership educators. Past research has indicated that increased structural diversity of a campus can benefit the students who attend (Antonio, 2001a; Antonio, 2001b; Bowman, 2013; Chang et al., 2006; Gurin et al., 2002; \& Laird, 2005). Similarly, findings presented here imply that students might benefit from increased racial diversity within the leadership sessions in which they participate. Notably, the benefits that students seemed to accrue from attending highly diverse sessions did not emerge until months after the session ended, long after students presumably put their new learning into practice within their own individual environments. While in general, scores crested for most students in the immediate aftermath of program participation and tapered significantly over time, scores seemed to taper the least in highly diverse sessions. In addition, the benefits were seen mostly in the internal states of being required for effective leadership - one's confidence and motivation to engage in leadership behaviors. This suggests that leadership sessions that are highly diverse may not materially affect the degree to which students acquire the tools to practice leadership behaviors, but they do bolster the degree to which students consider themselves leaders, feel called to lead, and possess a sense of self-confidence in engaging with peers as a leader.

These findings may indicate the degree to which the development of leadership capacity, especially the more internal parts of such capacity, is a social endeavor for university students. Thus, a curriculum that includes concepts of leadership that is inclusive, social justice-oriented, and based on collaborative relationships may not be enough in helping to maximize leadership development. However, the ability to create relationships with peers who are different from oneself, in an environment with a critical mass of peers similar to oneself, may be one key to unlocking long-term and sustainable growth in students. In an immersion program where students have the potential to create lasting relationships, a diverse population of participants might provide a better system of support for when applying the principles learned in the session becomes difficult over the ensuing months.

Lastly, we defined "low-diversity" as a session where any individual race other than White made up less than $15 \%$ of the overall population, and where students of color as a whole made up less than $50 \%$ of the population. These numbers are similar to the racial demographics of many university campuses within the United States. Given these similarities, our findings may 
help to inform our understanding of the processes of leadership learning that occur for students of color there.

Limitations and Suggestions for Future Research. The population for inclusion within this research study represented students who participated in a six-day immersion leadership program. While thousands of students participate in leadership education initiatives like this annually, our findings and their implications are limited by the nature of the program we examined. Further research should investigate the degree to which similar findings emerge in initiatives with a different structure, such as shorter-term or longer-term programs or academic courses. Presumably, the degree and shape of student inter-relationships built within these initiatives might look different; results might differ as well.

Additionally, our current study did not take into consideration the degree of structural racial diversity found on the campuses in which these leadership immersion programs took place. Future research should examine the degree to which campus diversity might serve as a moderating variable on results. Past research has shown the degree to which campus diversity can predict intellectual, civic, and social engagement (Antonio, 2001a; Bowman, 2013; Chang et al., 2006; Gurin et al., 2002). Presumably, highly racially diverse campuses might moderate the environment within a low-diversity session, and vice versa. Future research should determine the degree of moderation that exists between these two important variables.

While our findings suggest that students may be better off participating in high-diversity sessions, the factors that lead to these findings remain unexplained, and may be better examined through rigorous qualitative study. In-depth interviews that focus on students' experiences at high-diversity and low-diversity sessions, and how they relate their experiences to their leadership development, would lend depth to these findings and help leadership educators better maximize the potential for their students' leadership growth.

Lastly, due to the small size of student of color sub-samples in "low" diversity sessions, we were forced to collapse the various groups of students of color into a single group to compare to White students. While statistically appropriate, the practical conclusions that can be drawn are muddied due to the vast range of experiences that Asian American, Black, Hispanic/Latino, Multiracial and Indigenous American students face — particularly on predominantly white campuses. Future research should more effectively investigate the extent to which racial identity is associated with differences in leadership capacity development in the context of structure racial diversity in leadership sessions.

\section{Conclusion}

Although findings from the present sample indicate that, with respect to most outcome variables studied, the leadership capacity trajectories of participants did not differ significantly by race, the racial composition of the learning environment did make a difference for students. Unfortunately, with 17 "low" diversity sessions present in this sample, many students of color were not provided the opportunity to develop their leadership capacity in a space where they were not only one of a handful of non-White students. Not only does increased racial representation help students of color to avoid tokenization, but providing opportunities for 
diverse populations of students to interact in educationally meaningful ways can serve as a means to produce civic-minded leaders dedicated to positive social change.

Moreover, routinely low numbers of racial/ethnic minorities in studies of student leadership (Dugan, 2011), coupled with the substantial lack of women and racial minorities holding leadership positions in the nation's most influential public, private, and higher education sectors (Alliance for Board Diversity, 2013; Kim \& Cook, 2013; National Urban Fellows, 2012) calls into question the extent to which postsecondary institutions are fulfilling this duty (Astin, \& Astin, 2000; Guthrie, Jones, Osteen, \& Hu, 2013). As the nation becomes more racially diverse, it is more important than ever that postsecondary institutions do their part to provide equitable access to educationally meaningful activities - such as leadership development programs - for students from all backgrounds. Likewise, it is imperative that corporations and organizations recognize and recruit diverse graduates into the workforce - cultivating environments for their mobility and success.

\section{References}

Alliance for Board Diversity (2013). Missing pieces: Women and minorities on Fortune 500 boards. New York \& Washington: Alliance for Board Diversity.

Amit, K., \& Bar-Lev, S. (2013). Motivation to lead in multicultural organizations: The role of work scripts and political perceptions. Journal of Leadership \& Organizational Studies, 20(2), 169-184. https://doi.org/10.1177/1548051812467206

Antonio, A. L. (2001a). Diversity and the influence of friendship groups in college. The Review of Higher Education, 25(1), 63-89. doi: 10.1353/rhe.2001.0013

Antonio, A. L. (2001b). The role of interracial interaction in the development of leadership skills and cultural knowledge and understanding. Research in Higher Education, 42(5), 593617.

Arminio, J. L., Carter, S., Jones, S. E., Kruger, K., Lucas, N., Washington, J., \& al, e. (2000). Leadership experiences of students of color. NASPA Journal, 37(3), 496-510.

Astin, A. W., \& Astin, H. S. (2000). Leadership reconsidered: Engaging higher education in social change. Battle Creek, MI: W.K. Kellogg Foundation.

Avolio, B. J., Reichard, R. J., Hannah, S. T., Walumbwa, F. O., \& Chan, A. (2009). A metaanalytic review of leadership impact research: Experimental and quasi-experimental studies. The Leadership Quarterly, 20(5), 764-784.

https://doi.org/10.1016/j.leaqua.2009.06.006

Bass, B., \& Avolio, B. (1997). Revised manual for the Multi-Factor Leadership Questionnaire. Mind Garden, Palo Alto, CA. 
Bass, B. M. (1998). Transformational leadership. Hillsdale, NJ: Erlbaum.

Bowman, N. A. (2013). How much diversity is enough? The curvilinear relationship between college diversity interactions and first-year student outcomes. Research in Higher Education, 54, 874-894. doi: 10.1007/s11162-013-9300-0

Brown, M. E., Treviño, L. K., \& Harrison, D. A. (2005). Ethical leadership: A social learning perspective for construct development and testing. Organizational Behavior and Human Decision Processes, 97(2), 117-134.

Burns, J. M. (1978). Leadership. New York: Harper and Row.

Chan, K.-Y., \& Drasgow, F. (2001). Toward a theory of individual differences and leadership: Understanding the motivation to lead. Journal of Applied Psychology, 86(3), 481-498.

Chang, M. J., Denson, N., Saenz, V., \& Misa, K. (2006). The educational benefits of sustaining cross-racial interaction among undergraduates. The Journal of Higher Education, 77(3), 430-455.

Colby, S . L., \& Ortman, J. M. (2015). Projections of the size and composition of the U.S. population 2014 to 2060: Population estimates and projections. Current Population Reports, P25-1143. U.S. Census Bureau: Washington, D.C.

Cress, C. M., Astin, H., Zimmerman-Oster, K., \& Burkhardt, J. C. (2001). Developmental outcomes of college students' involvement in leadership activities. Journal of College Student Development, 42(1), 15-27.

DeAmicis, C., \& Carson, B. (2014, August 21). Eight charts that put tech companies' diversity stats into perspective. Retrieved from https://gigaom.com/2014/08/21/eight-charts-thatput-tech-companies-diversity-stats-into-perspective/.

Derue, D., \& Ashford, S. (2010). Who will lead and who will follow? A social process of leadership identity construction in organizations. Academy of Management Review, 35(4), 627-647. https://doi.org/10.5465/AMR.2010.53503267

Dinh, J. E., Lord, R. G., Gardner, W. L., Meuser, J. D., Liden, R. C., \& Hu, J. (2014). Leadership theory and research in the new millennium: Current theoretical trends and changing perspectives. The Leadership Quarterly, 25(1), 36-62. https://doi.org/http://dx.doi.org/10.1016/j.leaqua.2013.11.005

Dugan, J. P. (2006). Explorations using the social change model: Leadership development among college men and women. Journal of College Student Development, 47(2), 217225. doi: $10.1353 / \mathrm{csd} .2006 .0015$ 
Dugan, J. P. (2011). Research on college student leadership development. In The Handbook for student leadership development (2nd ed., pp. 59-85). San Francisco, CA: John Wiley \& Sons.

Dugan, J. P., \& Komives, S. R. (2007). Developing leadership capacity in college students: Findings from a national study. A report from the Multi-Institutional Study of Leadership. College Park, MD: National Clearinghouse for Leadership Programs.

Dugan, J. P., Garland, J. L., Jacoby, B., \& Gasiorski, A. (2008). Understanding commuter student self-efficacy for leadership: A within-group analysis. NASPA Journal, 45(2), $282-310$.

Dugan, J. P., Kodama, C. M., \& Gebhardt, M. C. (2012). Race and leadership development among college students: The additive value of collective racial esteem. Journal of Diversity in Higher Education, 5(3), 174-189. http://doi.org/10.1037/a0029133.

Dugan, J. P., \& Komives, S. R. (2010). Influences on college students' capacities for socially responsible leadership. Journal of College Student Development, 51(5).

Dugan, J. P., Komives, S. R., \& Segar, T. C. (2008). College student capacity for socially responsible leadership: Understanding norms and influences of race, gender, and sexual orientation. NASPA Journal, 45(4), 475-500.

Gratz v. Bollinger, 539 U.S. U.S. 244 (2003).

Grutter et al. v. Bollinger, 539 U.S. 306 (2003).

Gurin, P., Dey, E. L., Hurtado, S., \& Gurin, G. (2002). Diversity and higher education: Theory and impact on educational outcomes. Harvard Educational Review, 72(2), 330-366.

Guthrie, K. L., Jones, T. B., Osteen, L., \& Hu, S. (2013). Cultivating leader identity and capacity and students from diverse backgrounds: ASHE Higher Education Report. San Francisco, CA: John Wiley \& Sons.

Gutiérrez, R. (2011). The drama of diversity and democracy (Second ed.). Washington, DC.

Hannah, S. T., Avolio, B. J., Luthans, F., \& Harms, P. D. (2008). Leadership efficacy: Review and future directions. The Leadership Quarterly, 19(6), 669-692.

Hoyt, C. L. (2005). The role of leadership efficacy and stereotype activation in women's identification with leadership. Journal of Leadership and Organizational Studies, 11(4), $2-14$.

Huck, S.W. \& McLean, R.A. (1975). Using a repeated measures ANOVA to analyze the data from a pretest-posttest design: A potentially confusing task. Psychological Bulletin, 82(4), 511-518. Doi: 10.1037/h0076767. 
Hurtado, A. (2003). Voicing Chicana feminisms: Young women speak out on sexuality and identity. NYU Press.

Hurtado, S. (2007). Linking diversity with the educational and civic missions of higher education. The Review of Higher Education, 30(2), 185-196. doi: 10.1353/rhe.2006.0070

Hurtado, S., Milem, J. F., Clayton-Pederson, A. R., \& Allen, W. R. (1998). Enhancing campus climates for racial/ethnic diversity: Educational policy and practice. The Review of Higher Education, 21(3), 279-302.

Keating, K., Rosch, D. M., \& Burgoon, L. (2014). Developmental readiness for leadership: The differential effects of leadership courses on creating "ready, willing, and able" leaders. Journal of Leadership Education, 13(3), 1-16. doi: 1012806/V13/I3/R1

Kezar, A. J., \& Moriarty, D. (2000). Expanding our understanding of student leadership development: A study exploring gender and ethnic identity. Journal of College Student Development, 41(1), 55-69.

Kim, Y. M., \& Cook, B. J. (2013). On the pathway to the presidency 2013: Characteristics of higher education's senior leadership. Washington, DC: American Council on Education.

Laird, T. F. N. (2005). College students' experiences with diversity and their effects on academic self-confidence, social agency, and disposition toward critical thinking. Research in Higher Education, 46(4), 365-387. doi: 10.1007/s11162-005-2966-1

Machida, M., \& Schaubroeck, J. (2011). The role of self-efficacy beliefs in leader development. Journal of Leadership \& Organizational Studies, 18(4), 459-468. https://doi.org/10.1177/1548051811404419

McMahon, W. W. (2009). Higher learning, greater good: The private and social benefits of higher education. Baltimore, MD: Johns Hopkins University Press.

Murphy, S. E. (1992). The contribution of leadership experience and self-efficacy to group performance under evaluation apprehension. (Ph.D. 9230410), University of Washington, United States -- Washington. Retrieved from http://search.proquest.com/docview/304005264?accountid=14553 ProQuest Dissertations $\&$ Theses (PQDT) database.

Murphy, S. E., \& Ensher, E. A. (1999). The effects of leader and subordinate characteristics in the development of leader-member exchange quality. Journal of Applied Social Psychology, 29(7), 1371-1394. doi: 10.1111/j.1559-1816.1999.tb00144.x

National Urban Fellows, \& The MWM Consulting Group, LLC (2012). Diversity counts: Racial and ethnic diversity among public service leadership. Retrieved from http://www.nuf.org/sites/default/files/Documents/NUF_diversitycounts_V2FINAL.pdf 
Nilsson, J. E., Marszalek, J. M., Linnemeyer, R. M., Bahner, A. D., \& Misialek, L. H. (2011). Development and assessment of the Social Issues Advocacy Scale. Educational and Psychological Measurement, 71(1), 258-275. doi: 10.1177/0013164410391581

Owen, J. (2012). Examining the design and delivery of collegiate student leadership development programs: Findings from the Multi-Institutional Study of Leadership (MSLIS), a national report. Washington, DC: Council for the Advancement of Standards in Higher Education.

Page, S. E. (2008). The difference: How the power of diversity creates better groups, firms, schools and socities. Princeton, NJ: Princeton University Press.

Park, H., Keller, J., \& Williams, J. (2016, February, 26). The faces of American power, nearly as White as the Oscar nominees. The New York Times. Retrieved from https://www.nytimes.com/interactive/2016/02/26/us/race-of-american-power.html?_r=0.

Pike, G. R., \& Kuh, G. D. (2006). Relationships among structural diversity, informal peer interactions and perceptions of the campus environment. The Review of Higher Education, 29(4), 425-450. doi: 10.1353/rhe.2006.0037

Podsakoff, P. M., MacKenzie, S. B., Moorman, R. H., \& Fetter, R. (1990). Transformational leader behaviors and their effects on followers' trust in leader, satisfaction, and organizational citizenship behaviors. The Leadership Quarterly, 1(2), 107-142. doi: 10.1016/1048-9843(90)90009-7

Rosch, D. M. (2014). Predicting student leadership in agricultural professional preparation organizations. NACTA Journal, 58(1), 7-10.

Rosch, D. M., Collier, D., \& Thompson, S. E. (2015). An exploration of students' motivation to lead: An analysis by race, gender, and student leadership behaviors. Journal of College Student Development, 56(3), 286-291.

Rosch, D. M., Stephens, C. M., \& Collins, J. D. (2015). The LeaderShape Institute: Developmental gains in student leadership capacity. A report from LeaderShape, Inc. Champaign, IL: LeaderShape, Inc.

Rost, J. C. (1993). Leadership for the 21 st Century. Westport, CT.: Praeger Publishers.

Shertzer, J. E., \& Schuh, J. H. (2004). College student perceptions of leadership: Empowering and constraining beliefs. NASPA Journal, 42(1), 111-131.

U.S. Census Bureau (2012). Statitistical abstract of the United States: 2012. 
U.S. Department of Education. Institute of Education Sciences, National Center for Education Statistics (2016). Digest of Education Statistics, 2015 (NCES 2016 -014), Chapter 3. Retreived from https://nces.ed.gov/fastfacts/display.asp?id=98

Yukl, G. (2010). Leadership in organizations (7th ed.). Upper Saddle River, NJ: Prentice Hall.

\section{Author Biographies}

Jasmine D. Collins is Assistant Professor of Agricultural Leadership Education at the University of Illinois at Urbana-Champaign. Her research focuses on understanding how factors such as student social identity, campus/classroom racial climate, and sociopolitical contexts in the U.S. influence the development of college students as socially responsible leaders. jdcolli2@illinois.edu.

David M. Rosch is Associate Professor in the Agricultural Education Program at the University of Illinois at Urbana-Champaign, where his teaching and research is focused on the leadership development of emerging adults. dmrosch@illinois.edu. 